УДК 811.134.3

ББК 81.472.2

DOI: https://doi.org/10.17308/lic.2021.2/3421

\title{
СОФИЯ ДЕ МЕЛЛО БРЕЙНЕР АНДРЕСЕН: ПОЭТИКА «ИЗУМЛЕНИЯ»
}

\author{
К. К. Нечаева, В. А. Махортова \\ Московский государственный лингвистический университет
}

\section{SOPHIA DE MELLO BREYNER ANDRESEN: THE POETRY OF "AMAZEMENT"}

\author{
K. K. Nechaeva, V. A. Makhortova \\ Moscow State Linguistic University
}

\begin{abstract}
Аннотация: в статье представлен анализ поэзии Софии де Мелло Брейнер Андресен (1919-2004), признанного классика португальской литературы ХХ в. Цель исследования состоит в том, чтобы дать обоснование эстетическому эффекту восторга/изумления, который, согласно мнению португальских литературных критиков и ученых, наиболее характерен для лирики автора. Анализ проведен на материале стихотворений, включенных в сборник «Собрание сочинений» («Obra рое́tica», 2015). Теоретической базой исследования служат положения когнитивной поэтики Р. Цура и эстетическая концепџия И. Канта. Работа выполнена с применением метода сплошной выборки, количественного метода, а также методов контекстуального, стилистического и семантического анализа. В ходе исследования установлено, что репрезентация Прекрасного и Возвышенного составляет одну из констант творчества Софии де Мелло. Соответствуюшие образы имеют системный характер в лирике португальской поэтессы. $K$ предметам, включенным в категорию Прекрасного, в поэзии автора относятся как элементы природного мира (61\%), так и артефакты (39\%). Наиболее частотны и значимы образы цветка, острова, дома, к которым поэтесса обращается на протяжении всего своего творчества, актуализируя такие их признаки, как «красота», «целостность» и «совершенство формыл». Воплощением Возвышенного для автора является природа, а именно: морское, небесное пространства, равнины и пустыни. Наиболее часто автор обращается кморским пейзажам, сочетающим в себе все характеристики Возвышенного: безграничный простор, высоту и интенсивный шум волн, связь с отдаленным временем и с вечностью, а также абсолютную тишину и темноту, свойственные морским глубинам. Эффект восторга/изумления перед Прекраснылм и Возвышенным в поэзии Софии де Мелло усиливается за счет использования стилистических средств. Описывая предметы и явления окружающего мира, поэтесса отдает предпочтение конкретным именам существительным, использует прием вербализации ощущений, в том числе в синестетическом ключе, а также метафоры с периептивным компонентом. Использование глаголов чувственного восприятия, преимущественно зрительной модальности, позволяет «расположить» предмет перед глазами читателя. Таким образом, эффект восторга/изумления в поэзии Софии де Мелло достигается благодаря выбору тематики, а также языковых средств и стилистических приемов, наиболее адекватных для реалистичного изображения прекрасных и возвышенных предметов и явлений действительности.

Ключевые слова: когнитивная лингвистика, когнитивная поэтика, София де Мелло Брейнер Андресен, португальский язык, португальская литература, вербализация ощущений, синестезия.
\end{abstract}

Abstract: the article analyses the poetry of Sophia de Mello Breyner Andresen (1919-2004), one of the main Portuguese poets of the 20th century, and aims to substantiate the aesthetic effect of delight/amazement, which, according to Portuguese literary critics and scholars, is characteristic of the author's lyrics. The analysis was carried out on the material of poems from the collection "Obra poética" (2015). Theoretically the research is

(C) Нечаева К. К., Махортова В. А., 2021

Контент доступен под лицензией Creative Commons Attribution 4.0 License.

The content is available under Creative Commons Attribution 4.0 License. 
based on the cognitive poetics of R. Tsur and the aesthetic conception of I. Kant. The methods include continuous sampling, the quantitative method, contextual, stylistic and semantic analysis. The results of the study show that the representation of the Beautiful and the Sublime is one of the constants of Sophia de Mello's poetry. In the authors lyrics the category of the Beautiful is represented by the elements of the natural world (61\%) and artifacts (39\%). The main representations of the Sublime include the sea, the sky, the plains and the deserts. Most often, the author refers to seascapes that combine all the characteristics of the Sublime: boundless space, height and intense sound of waves, connection with distant time and eternity, as well as absolute silence and darkness inherent in the depths of the sea. The effect of delight/amazement caused by the aesthetic contact with the Beautiful and Sublime is strengthened by the use of linguistic and stylistic means. Describing objects and phenomena of the surrounding world, the poet gives preference to the concrete nouns, uses the technique of sense verbalization, including in a synesthetic key, as well as metaphors with a perceptual component. All this contributes to the realism of the created images and enhances their influence on the reader.

Key words: cognitive linguistics, cognitive poetics, Sophia de Mello Breyner Andresen, the Portuguese language, the Portuguese literature, sense verbalization, synaesthesia.

\section{Введение}

София де Мелло Брейнер Андресен (1919-2004) по праву входит в число наиболее значимых фигур португальской литературы XX в. Известный португальский критик Эдуардо Лоуренсо определяет ее поэзию как поэзию «созерцания и восторга» $[1$, p. 198]. Близкой точки зрения придерживаются филологи Карлос Сейя [2] и Катарина Нунеш Алмейда, по мнению которой все творчество поэтессы представляет собой «поэтику плаваний и изумления» $[3$, p. 60]. Утверждения португальских исследователей указывают не только на содержательную сторону поэзии автора, но и на тот эффект, который она оказывает на читателя. При этом в смыссловом и образном плане, как справедливо отмечает Е. А. Ряузова, поэзии Софии де Мелло свойственна «верность реальному (миру - прим. авт.)» [4, с. 12], что подчеркивала и сама поэтесса. «Поэзия всегда была для меня погоней за сущим. А стихотворение - кругом, очерчивающим предмет, кругом, в который поймана птица сущего» [5, с. 254], - пишет София де Мелло в эссе из цикла «Искусство поэзии». Иными словами, стихотворение служит для того, чтобы запечатлеть определенный предмет, событие, момент действительности, что обусловливает «фотографический характер» ${ }^{1}$ лирики автора, которую в плане выражения отличают лаконичность изобразительных средств, отсутствие украшательства, или, как утверждает писатель Эдуардо Прадо Коэльо, «прозрачность языка» [7, р. 20].

\section{Цель, материалы, методы и теоретические основы исследования}

Цель нашей статьи состоит в том, чтобы обосновать свойственный поэзии Софии де Мелло эффект восторга/изумления, выявив связи между образно-

${ }^{1}$ Вслед за бразильской исследовательницей Наталией Нахас фотографическим мы называем стихотворение, которое «служит для репрезентации предметов и явлений окружающего мира, позволяя читателю явственно представить их и ощутить свою связь с ними» [6, p. 101]. стью, языковыми и стилистическими особенностями ее стиха, с одной стороны, и воздействием ее произведений на читателей - с другой. В качестве материала исследования нами выбрано «Собрание сочинений» («Obra Poética») Софии де Мелло [8], включающее около 700 стихотворений. В работе применяются метод сплошной выборки, количественный метод, а также методы контекстуального, стилистического и семантического анализа. Теоретической основой служат когнитивная поэтика Р. Цура, призванная «систематически связать особенности структуры литературных текстов и их воспринимаемые эффекты» [9, с. 92], а также эстетическая концепция И. Канта, посвященная осмыслению категорий Прекрасного и Возвышенного.

Основная гипотеза Р. Цура состоит в том, что «поэзия задействует обычные когнитивные механизмы в эстетических целях» [10, р. 4], что в той или иной степени требует модификации данных механизмов. В частности, к числу важнейших когнитивных способностей человека Р. Цур относит способность ориентироваться в пространстве, которая предполагает: 1) восприятие отдельных предметов; 2) определение своего положения относительно них. Отмечая, что оба механизма используются в поэзии, Р. Цур соотносит их с рассматриваемыми И. Кантом эстетическими категориями Прекрасного и Возвышенного [10, p. 350]. Чувство Прекрасного, по Канту, возникает при восприятии обособленных, целостных предметов, обладающих совершенной формой. Прототипом такого предмета («прекрасной вещи») для И. Канта является цветок [11, с. 294]. Следовательно, категория Прекрасного связана с первым из упомянутых выше когнитивных механизмов. Чувство Возвышенного, в свою очередь, представляет собой впечатление от объектов, обладающих безграничной величиной или мощью и поэтому превосходящих возможности непосредственного чувственного восприятия. В качестве наиболее типичных примеров Возвышенного И. Кант называет «вид звездного неба» 
и «зрелище бури» [11]. Как поясняет Р. Цур, чувство Возвышенного в большей мере связано со вторым когнитивным механизмом, поскольку предполагает определение позиции наблюдателя относительно безграничных пространств [10, p. 350]. Возвращаясь к эстетической концепции И. Канта, обратим внимание на то, что Прекрасное и Возвышенное вызывают разные эмоции у наблюдателя. Прекрасное доставляет радость [12, с. 123], в то время как Возвышенное поражает зрителя, заставляя его одновременно испытывать «удовольствие и страх» [12, с. 128]. Данные эмоциональные реакции нам представляется возможным соотнести с состоянием восторга и изумления (Ср.: восторг - «сильный подъем радостных чувств» [13]; изумление - «очень большое удивление, состояние пораженности» [14]). Учитывая все вышеизложенное, обратимся к исследованию поэзии Софии де Мелло.

\section{Результаты исследования}

Анализ произведений Софии де Мелло, написанных в разные годы, позволяет установить, что описание Прекрасного и Возвышенного составляет одну из постоянных характеристик творчества автора. К «прекрасным вещам», находящим репрезентацию в лирике поэтессы, относятся как предметы природного мира (61 \%), так и артефакты (39\%). Соответствующая классификация представлена в таблице. Цифрами отмечено количество стихотворений, включающих прямую номинацию предмета. Курсивом выделены ключевые образы поэзии Софии де Мелло, значимость которых подтверждается не только частотностью, но и идейно-смысловым и ассоциативным потенциалом.

Примечательно, что «прекрасные вещи» в поэзии автора выступают не только как элементы более сложных образов (например, цветок как часть сада

Т а б ли ц а

Прекрасное в поэзии Софии де Мелло

\begin{tabular}{|c|c|c|}
\hline \multicolumn{2}{|r|}{ Предметы природного мира - 61 \% } & Артефакты - 39 \% \\
\hline Растительный мир & $\begin{array}{l}\text { Цветок (55) - роза (13) - нард (4) - нарцисс (3); } \\
\text { Плод (27) - яблоко (2); } \\
\text { Дерево (25) - сосна (7) - кипарис (5) - липа (2); } \\
\text { Плющ (4); } \\
\text { Ветка оливы (1) }\end{array}$ & \multirow[t]{2}{*}{$\begin{array}{l}\text { Дом (50) - окно (14) - зеркало (12) - веранда (1); } \\
\text { Стамуя (23); } \\
\text { Амфора (9); } \\
\text { Музыкальные инструменты: арфа (7), флейта (6); } \\
\text { Ширма намбан (1) }\end{array}$} \\
\hline Морская природа & $\begin{array}{l}\text { Остров (29); } \\
\text { Ракушка (10); } \\
\text { Жемчужина (4); } \\
\text { Коралл (2) }\end{array}$ & \\
\hline
\end{tabular}

или сосна как деталь пейзажа), но и как основные предметы описания в стихотворениях, которые по аналогии с творчеством Р. М. Рильке мы относим к жанру стихотворения-вещи. Характеризуя этот жанр, Н. Г. Лютикова пишет: «Каждое слово, каждый эпитет или образ... всецело подчинялись строго очерченной теме, все лишнее исчезало. При богатой образности, которая по-прежнему украшала стихи Рильке, создавалось впечатление экономии средств выражения» [15, с. 7]. Все это справедливо и для вещных стихотворений Софии де Мелло, к которым относятся «Белый дом»,

\footnotetext{
As Rosas

Quando à noite desfolho e trinco as rosas

É como se prendesse entre os meus dentes

Todo o luar das noites tranparentes,

Todo o fulgor das tardes luminosas,

$\mathrm{O}$ vento bailador das Primaveras,

A doçura amarga dos poentes,

E a exaltação de todas as esperas.
}

«Розы», «Цветы», «Статуя», «Флейта», «Ширмы намбан», «Остров Принца», «Арфа», «Плющ», «Ракушка с острова Кос» и многие другие. Все их объединяет то, что создаваемые в них образы совершенных предметов не утрачивают своей связи с действительностью, но, напротив, обладают высокой реалистичностью. София де Мелло не только и не столько описывает более или менее привычные вещи, но «показывает их... так, будто они находятся перед глазами писателя и слушателя или читателя» [16, p. 176]. Рассмотрим эти особенности на примере стихотворения-вещи «Розы»:
Розы
Когда губами лепестков касаюсь розы, Мне кажется, как будто скрыты в ней
Весь лунный блеск безоблачных ночей
И все сияние дневного солнца,
Весенний ветер, легкий, безмятежный,
И сладость горькая истаявших лучей, И ожиданья все, и все надежды ${ }^{2}$. (Перевод В. Махортовой)

2 Здесь и далее переводы приведены по изданию: Андре$c е н ~ C$. Единое начало всех вещей : избранные стихотворения. M., 2019. 
Как и в других вещных стихотворениях, в заглавии автор использует соответствующее предмету (в данном случае - розам) конкретное существительное, «имя вещи», называя которое, «представляет» этот предмет читателю. Существительное «розы», фигурирующее также в первой строке, является отправной точкой развития стихотворения, подчиненного принципу «сказать - значит показать, объявить, дать видеть, слышать» [16, с. 265]. Во всем стихотворении имена существительные находятся в интонационно сильных позициях, выполняют роль смысловых центров, что отражает «субстантивный характер лирики автора» $[17$, p. 19]. Сочетание лексем конкретной и абстрактной семантики воспроизводит переход от восприятия роз как материального предмета к постижению их красоты. Эта направленность отражена в стихотворении в целом. В первой строке акцент делается на непосредственном перцептивном взаимодействии с предметом, что подчеркнуто использованием глагола чувственного восприятия «касаться» ${ }^{3}$, в то время как далее автор переходит к метафорическому описанию роз, подчеркивая качества розы, присущие ей как воплощению Прекрасного. Используя метафоры, включающие перцептивный компонент, поэтесса выражает идею принадлежности Прекрасного реальному миру. Красота розы уподобляется «лунному блеску» и «сиянию дневного солнца». Обе метафоры строятся на основе зрительной модальности, необходимой для восприятия света. Оксиморон «сладость горькая» актуализирует вкусовую модальность и передает двойственность розы как совершенного, но хрупкого предмета. Кульминацией стихотворения является последняя строка, в оригинальном тексте включающая в себя абстрактное существительное «ехaltação» («восторг»), соответствующее восприятию Прекрасного. Таким образом, все стихотворение сконцентрировано вокруг одного предмета, который поэтесса стремится «показать» читателю. При этом реалистичность, или фотографичность, созданного автором образа усиливает эстетический эффект соприкосновения с Прекрасным.

Эти же характеристики проявляются и в других вещных стихотворениях автора, которые заслуживают отдельного подробного анализа. Здесь же обзорно рассмотрим некоторые стратегии поэтессы, непосредственно связанные с эстетическим воздействием ее стихотворений. Реалистичность изображения, усиливающая чувство Прекрасного, в лирике Софии де Мелло подчеркивается вербализацией ощущений: использованием глаголов и имен существительных

${ }^{3} \mathrm{~B}$ оригинальном тексте описана ситуация еще более активного взаимодействия с предметом: «Quando à noite desfolho e trinco as rosas», что дословно означает: «Когда обрываю и пробую на вкус лепестки роз». чувственного восприятия, а также обозначением сенсорных свойств предмета, преимущественно цвета. Наиболее частотны номинации зрительного восприятия. Ср.: И вдруг открылась взглядам нашим россыпь / Лазурных островов (цикл «Плавания», «Острова», I); Остров Принияа, воспетый Синатти, / Медленно появлялся / Перед глазами поэта («Остров Принца»); Поэтому, если вижу в музейных залах / Античные статуи, фризы или колонны («Меня научило море») и др. Цветообозначения, также связанные со зрительной модальностью, включают основные цвета: белый дом; плющза зеленый полог; а также оттенки: цъветок карминно-красный; кипарисов темная зелень $и$ др. В стихотворениях, посвященных музыкальным инструментам, София де Мелло делает акцент на акустической характеристике, призывая читателя представить звук древних инструментов, которые в творчестве поэтессы ассоциативно связаны с античным миром, выступающим как символ совершенства. Ср.: Тень опустилась ночная, и звуки посльшились флейты («Флейта»); Муза в комнату входит и против света / Тонкострунную ставит арфу, / А затем прикасается к звонким / Струнам («Арфа»). В последнем примере звуковая модальность синестетически дополняется зрительной (восприятием света) и тактильной. Стихотворение «Ширмы намбан», посвященное предмету японского искусства XVI-XVII вв., примечательно удвоением эстетического эффекта. Во-первых, София де Мелло выбирает предмет, привлекающий внимание европейского читателя или наблюдателя необычностью и изяществом. А во-вторых, средствами языка «оживляет» изображенные на ширме сцены, отсылающие к моменту встречи двух культур: португальской и японской. Используя конкретные существительные, поэтесса перечисляет предметы, впервые оказавшиеся перед глазами португальских мореплавателей: Лаки , взмахи веера, / Кимоно, камелии, а также отражает взаимодействие путешественников с новой культурной средой, в синестетическом ключе объединяя зрительную (Все неведомое - рядом / И теперь открыто взгляду) и ольфакторно-вкусовую (Пряность новых вкусов) модальности. В заключительных строках автор передает чувство, которое охватывает моряков, соприкоснувшихся с реальностью, превосходящей ожидание: Веселясь, ликуя, пляшут - / Мир у них перед глазами / Оказался ещзе краше, / Чем они предполагали. Интерес современного наблюдателя, смотрящего на изящную японскую ширму, совмещается с восторгом мореплавателей, открывших для себя новый мир. Итак, к категории Прекрасного поэтесса относит разнообразные предметы: от маленького цветка до острова, от привычного окна до необычной

4 Лаковые миниатюры. 
японской ширмы. Вместе с тем изображение этих вещей, на наш взгляд, носит не случайный, но закономерный характер и соответствует стремлению автора видеть все «великолепие мира» [5, с. 254].

Не менее значима в поэзии Софии де Мелло категория Возвышенного. Ссылаясь на трактат поэта Шломо Левисона, к характеристикам возвышенного объекта Р. Цур относит: «огромные расстояния, предельные высоты и глубины, отдаленное прошлое, очень громкий звук, а также абсолютную тишину и

\section{Mar sonoro}

Mar sonoro, mar sem fundo, mar sem fim, A tua beleza aumenta quando estamos sós E tão fundo intimamente a tua voz Segue o mais secreto bailar do meu sonho, Que momentos há em que eu suponho Seres um milagre criado só para mim.

Следуя единому творческому методу, автор фотографически воссоздает элемент окружающей действительности. Конкретное существительное «mar» («море») выполняет номинативную функцию, задавая основную тему стихотворения. Прилагательное «sоnoro» («шумный») используется для вербализации слухового восприятия моря. Эта же характеристика подчеркнута существительным «Voz» («голос»), персонифицирующим морскую стихию. Кроме того, иконически шум моря передан звукоподражательной аллитерацией - повторением согласных «s», «f»: Mar sonoro, mar sem fundo, mar sem fim. Гиперболы sem fundo (бездонное) и sem fim (бесконечное) характеризуют море как пространство, не имеющее границ. Протяженность моря подчеркивается тройным повтором существительного «mar» («море»), в чем проявляется принцип иконического количества. Абстрактное существительное «beleza» («красота») служит для выражения высокой эстетической оценки моря, в то время как метафора «море - чудо» передает чувство изумления, вызванное созерцанием морского простора (Ср. «чудо - феномен, чудо природы... изумительный» [18]). Вид и шум моря захватывают наблюдателя, чему соответствует свойственный лирике Софии де Мелло эффект «растворения в пейзаже» [19, р. 67]. К средствам создания этого эффекта мы можем отнести метафору «раздается голос твой во мне», переносящую звук моря из внешнего мира во внутренний мир лирического «Я», а также кольцевую рифму «sem fim»- «em mim» (дословно: «бесконечное - во мне»), связывающую безграничную морскую даль и наблюдателя. Итак, с одной стороны, автор фокусирует внимание читателя на перцептивной (главным образом акустической) характеристике моря, а с другой - подчеркивает его темноту» [10, p. 353]. Наряду с неограниченной мощью, рассматриваемой И. Кантом как атрибут Возвышенного, все они свойственны объектам природного мира, изображенным в пейзажной лирике португальской поэтессы. Репрезентантами Возвышенного в поэзии Софии де Мелло выступают море (74 \%), небо (17\%), равнины и пустыни (9\%). Главную роль играет морская стихия, репрезентация которой представлена, в частности, в стихотворении «Mar sonoro» («Море шумное»):

\section{Шумное море}

Море шумное - ни берега, ни дна, Ты красивей, если мы наедине, Раздается голос твой во мне, И созвучен он моим мечтам, Словно песня, данная волнам, Для меня, и только, создана. (Перевод В. Махортовой)

огромную величину, делающую невозможным установление его границ, что усиливает чувство изумления.

Прием одновременной актуализации перцептивных и превосходящих чувственное восприятие характеристик используется и в других контекстах, в которых море представлено как носитель всех основных атрибутов Возвышенного. Море изображено как бесконечное пространство, исполненное зрительно воспринимаемого света: Светлы бескрайние морские дали («В открытом море»). Единственными видимыми границами моря (океана) $)^{5}$ являются побережье, разделяющее океанский простор и сушу, и горизонт, проходящий между океаном и небом. Однако сами эти границы обладают огромной протяженностью: Существуют простор побережнй и моря бескрайняя дума («Город»); Высокий и широкий горизонт / Расивечен сладостным огнем заката («Начало лета»). Высота присуща не только горизонту, но и морским волнам: Вновь себя обретаю, с волнами стремясь в высоту («Я не нашла себя»). При создании образа волн зрительная модальность может дополняться акустической и ольфакторной: Лишь заnax волны, неприрученной, дикой, / Взмывающей в небо к высоким созвездьям, / Подобно пронзительно чистому крику («Море»). В данном случае эффект безграничной высоты и стремительности (силы) волн умножается за счет уподобления этих качеств громкости звука (крика). Противоположная высоте характеристика Возвышенного - глубина, также свойственна морю: А на востоке море шумит бездонное («Лиссабон»). Менее очевидна, но существенна для поэзии

${ }^{5}$ В португальском языке существительное «mar» означает одновременно «море» и «океан». Dicionário Online Priberam. Disponível em: https://dicionario.priberam.org/mar 
Софии де Мелло связь морской стихии и отдаленного прошлого. В лирике поэтессы море (океан) и побережье не только ассоциативно связаны с историческими периодом античности и эпохой великих географических открытий, но также изображены как исконные, первоначальные, иными словами, существующие с древнейших времен. Это те места, где «все истинно и первозданно» («Свобода»). В отличие от остальных качеств моря: протяженности, высоты волн, глубины, блеска поверхности, шума, временная характеристика чувственно не воспринимаема. Однако все первоначальное в лирике Софии де Мелло обретает реалистичное воплощение: «Синеет море, гребни волн белеют, / Блестят омытые прибоем камни, / И все имеет облик первозданный» («Начало»). Использование конкретных существительных: море, гребни, волны, камни, а также вербализация зрительно воспринимаемых качеств: синеет, белеют, блестят, - позволяют читателю представить соответствующий пейзаж. Включая море в циклическое, природное время, противопоставленное линейному, историческому времени, София де Мелло изображает его как средоточие неиссякаемой силы. Мощь морской стихии поэтесса передает через описание постоянного движения волн, воспринимаемого на основе зрительной модальности, и несмолкающего морского шума, акустической характеристики моря. Сочетание этих модальностей проявляется, например, в следующих строках: Океан похож на спрута - / Крепких мыши клубок зеленый, / Вечно двиюсущцийся хаос, / Равномерный иум прибоя («Открытие»). Абсолютные тишина и темнота как атрибуты Возвышенного и характеристики моря реже оказываются в центре авторского внимания, однако именно они соотносятся с пейзажами морского дна (см., например, стихотворение «На дне морском»).

Небо также обладает всеми качествами Возвышенного, что отражено в поэзии Софии де Мелло. Безграничность неба передана в следующих строках: Бескрайнее небо глядится в его / Невидящие глаза («Мертвый солдат»), И где так светел простор небосвода («Свобода»), Я видел волны, мысыl, иирь небес («Плавания», «Дрейф», VIII). Это качество связано, прежде всего, со зрительной модальностью, причем в качестве наблюдателя выступает как лирический герой (Я видел...), так и само небо (небо глядится). Как и неограниченный простор, абсолютная высота неба сочетается со светом или сиянием: И восхитительным мгновенье было, / Когда под небом светльмм и высоким / Открылась синь Востока и сапфиров («Плавания», «Острова», IV); Когда созвездия сияют ясно / В высоких небесах («Мечта моя лететь к тебе навстречу»). Контекстуальная близость лексических единиц со значением «свет» и «высота», согласно иконическому принципу дистанции, пере- дает тесную связь между этими качествами. В лирике Софии де Мелло свет является главной характеристикой дневного неба, а также ночных светил. И хотя Ш. Левинсон не включает свет в число атрибутов Возвышенного, нам представляется связать его с этой категорией, благодаря наличию следующих символических значений света: бессмертие, вечность, величие [20, с. 324]. Помимо этого, свет поэтесса связывает с такими атрибутами Возвышенного, как абсолютная тишина и мощь. Строки: Сияют ярко / (...) Большие звезды / И полнят небо вечной тишиной («Ноктюрн Грасы») - передают сочетание интенсивного свечения звезд и полного отсутствия звука, восприятие которых предполагает действие визуальной и акустической модальностей. Эпитет «вечная», используемый для определения тишины, указывает на ее неизменность, связь с прошлым, настоящим и будущим. Неограниченной мощью в лирике Софии де Мелло наделены небесные светила: луна и солнце. В частности, метафора Магнит луны сияет голубой («Ноктюрн Грасы») указывает на силу притяжения, свойственную этому небесному телу как в прямом, физическом смысле, так и в переносном: луна выступает как объект, «притягивающий» взгляды наблюдателей. Зрительная модальность восприятия Луны передана за счет глагола «сияет» и цветообозначения «голубой». Та же модальность актуализирована в следующих примерах: Лунный свет в ночи рисует миражи, / И весь мир преображается вокруг («Лунный свет»); Где под луной, сиянием зажженной, / Дремали пальмы в тишине безмолвной («Плавания», «Дрейф», I) и др. Интенсивность лунного света подчеркнута его активным воздействием на окружающий мир (pucyem миражи), а также эпитетом «зажженный». Солнцу посвящены следующие строки: 1. Многоцяветье ярких красок мая / Солнца жгучие лучи снедают («Сад»); 2. власть всемогущего солнца («Ингрина»); 3. Тяжелая длань Солнияа ляжет тебе на плечи («Утренняя дорога»); 4. Горло мое пересохло, и солнияа / Беспредельная тяжесть давит на плечи («Путь») и др. Все эти примеры передают неограниченную силу солнечного света. При этом в первом контексте реализована метафора «солнечный свет - огонь», предполагающая визуальное и температурное (тактильное) восприятие. Второй пример представляет собой персонификацию солнца: «солнце - властелин», соответственно: «солнечный свет - власть». В основе третьего и четвертого примеров лежит метафора: «солнечный свет - тяжелый предмет», которая совмещает визуальную модальность и ощущение массы. Интенсивность солнечного света выражается также путем обозначения притупленной возможности зрительного восприятия: И под слепящцм солнцем шла нагая («Минотавр»); Плотный сумрак ночной там встречался с рассветом, / Ослепительно ярким, плени- 
тельно светльм («Дворец»). Схожий прием используется при описании пустыни и равнины: Ветер летит над равниной / Необозримой, /Сонной и молчаливой («Ветер»); И белая даль пустыни / Ослепила меня («Путь»). В обоих случаях лексические единицы, служащие для обозначения ограниченного зрительного восприятия, соответствуют идее протяженного пространства, которое не может быть охвачено взглядом.

Так, в поэзии Софии де Мелло основные характеристики Возвышенного, обозначенные И. Кантом и Ш. Левинсоном, соотносятся с перцептивными качествами, которые проявляются в предельно высокой или низкой степени. Безграничный размер, высота, глубина, темнота (отсутствие света) связаны со зрительной модальностью. Громкий звук и полная тишина (отсутствие звука) соотносятся с акустической модальностью. Мощь природных явлений также ощутима и передана через зрительную (интенсивный свет), звуковую (шум моря), тактильную (жар и «тяжесть» солнечного света) модальности. Временная характеристика Возвышенного, состоящая в его отнесенности к далекому прошлому, в лирике Софии де Мелло трансформируется, поскольку описываемые автором природные пространства характеризуются не только как древние, но и как вечные.

\section{Заключение}

Разделяя мнение португальских филологов и критиков, мы определяем поэзию Софии де Мелло как поэзию восторга или изумления. Результаты нашего исследования позволяют обосновать этот эффект, указывая на то, что он обусловлен как содержательной, так и языковой составляющей лирики автора. Образная структура поэзии Софии де Мелло включает в себя предметы и явления, относящиеся к категориям Прекрасного и Возвышенного (в кантовском понимании). К «прекрасным вещам» в творчестве автора относятся как объекты природного мира (цветок, остров и др.), так и объекты культурной сферы (дом, статуя и др.). Категории Возвышенного соответствуют изображения бескрайних просторов (морского пространства; неба; равнины и пустыни). Реалистичность образов, усиливающая свойственный поэзии Софии де Мелло эстетический эффект, достигается за счет используемых автором лексических средств и стилистических приемов, таких как преобладание конкретных имен существительных, вербализация ощущений, в том числе в синестетическом ключе, а также использование метафор с перцептивным компонентом. Все это позволяет поэтессе передать чувство соприкосновения с Прекрасным и Возвышенным.

\section{ЛИТЕРАТУРА}

1. Lourenço E. Dialética mítica da nossa modernidade // Lourenço E. Tempo e poesia. Lisboa : Relógio d'Água, 1987. Pp. 183-200.

2. Ceia C. Iniciação aos Mistérios da Poesia de Sophia de Mello Breyner Andresen. Lisboa : Vega, 1996. 162 p.

3. Nunes de A. C. O Feito, a Gesta e o Olhar : o Oriente nas Navegações de Sophia de Mello Breyner Andresen // Elyra. 2014. № 4. Pp. 57-78.

4. Из современной португальской поэзии / сост., предисл. и справки об авт. Е. А. Ряузовой. М. : Прогресс, 1980. $351 \mathrm{c}$.

5. Nery I. Sophia de Mello Breyner Andresen. Lisboa : A esfera dos livros, 2019. $333 \mathrm{p}$.

6. Nahas $N$. No espaço do poema: a presença do real na poesia de Sophia de Mello Breyner Andresen // Desassossego. 2017. № 18. Pp. 101-115.

7. Coelho E. P. Sophia : a lírica e a lógica // Revista Colóquio / Letras. 1980. № 57. Pp. 20-35.

8. Andresen S. M. B. Obra poética. Porto : Assírio \& Alvim, 2015. 992 p.

9. Лозинская E. В. Литература как мышление : когнитивное литературоведение на рубеже XX-XXI веков / РАН. ИНИОН. Центр гуманит. науч.-исслед. Отдел литературоведения. М., 2007. 160 с.

10. Tsur $R$. Toward a theory of cognitive poetics. Amsterdam : North-Holland, 1992. 573 p.

11. Эко У. История красоты. М. : СЛОВО/SLOVO, 2007. $437 \mathrm{c}$.

12. Кант И. Наблюдения над чувством Прекрасного и Возвышенного // Кант И. Собрание сочинений в 6 томах / под общ. ред. В. Ф. Асмуса, А. В. Гулыги, Т. И. Ойзермана. Т. 2. М. : Мысль, 1964. С. 125-185.

13. Современный толковый словарь русского языка / под ред. Т. Ф. Ефремовой. URL: https://dic.academic.ru/ contents.nsf/efremova/

14. Энциклопедический словарь по психологии и педагогике. URL: https://psychology_pedagogy.academic. $\mathrm{ru} /$

15. Лютикова Н. Г. Предисловие // Рильке Р. М. Книга Образов. СПб. : Терция, Кристалл, 1999. С. 5-8.

16. Хайдеггер М. Время и бытие / сост., пер. и ком. В. В. Бибихина. М. : Республика, 1993. С. 259-273.

17. Bonafim Felizardo A. O Lugar do Ser : espaço e lirismo em Sophia de Mello Breyner Andresen : tese de doutoramento. São Paulo, 2012. 267 p.

18. Тришин В. Н. Словарь синонимов ASIS. URL: https://dic.academic.ru/contents.nsf/dic_synonims/

19. Lopes S. R. Escutar, Nomear, Fazer Paisagens // Exercícios de Aproximação. Lisboa : Vendaval, 2003. Pp. 49-74.

20. Трессидер Дж. Словарь символов / пер. с англ. С. Палько. М. : Гранд : ФАИР-Пресс, 1999. 443 с. 


\section{REFERENCES}

1. Lourenço E. Dialética mítica da nossa modernidade. In: Lourenço E. Tempo e poesia. Lisboa: Relógio d'Água, 1987. Pp. 183-200.

2. Ceia C. Iniciação aos Mistérios da Poesia de Sophia de Mello Breyner Andresen. Lisboa: Vega, 1996. 162 p.

3. Nunes de A. C. O Feito, a Gesta e o Olhar: o Oriente nas Navegações de Sophia de Mello Breyner Andresen. In: Elyra. 2014. No. 4. Pp. 57-78.

4. Iz sovremennoj portugal'skoj poehzii [From the modern Portuguese poetry]. Ed. by E. A. Ryauzova. Moscow: Progress, 1980. 351 p.

5. Nery I. Sophia de Mello Breyner Andresen. Lisboa: A esfera dos livros, 2019. 333 p.

6. Nahas N. No espaço do poema: a presença do real na poesia de Sophia de Mello Breyner Andresen. In: Desassossego. 2017. No. 18. Pp. 101-115.

7. Coelho E. P. Sophia: a lírica e a lógica. In: Revista Colóquio / Letras. 1980. No. 57. Pp. 20-35.

8. Andresen S. M. B. Obra poética. Porto: Assírio \& Alvim, 2015. 992 p.

9. Lozinskaya E. V. Literatura kak myshlenie: kognitivnoe literaturovedenie na rubezhe XX-XXI vekov [Literature as cognition: cognitive poetics on the cusp of the 20th and 21 st centuries] / RAN. INION. TSentr gumanit. nauch.issled. Otdel literaturovedeniya. Moscow, 2007. 160 p.

10. Tsur R. Toward a theory of cognitive poetics. Amsterdam: North-Holland, 1992. 573 p.

11. Eco U. Istoriya krasoty [The history of beauty] Moscow: SLOVO, 2007. 437 p.

Московский государственный лингвистический университет

Нечаева К. К., кандидат филологических наук, и. о. заведуюшей кафедрой португальского языка

E-mail:nechaeva.ksk@mail.ru

Махортова В. А., аспирант кафедры португальского языка

E-mail: varvara2504@mail.ru

Поступила в редакичию 1 февраля 2021 г.

Принята к публикачии 22 марта 2021 2.

\section{Для цитирования:}

Нечаева К. К., Махортова В. А. София де Мелло Брейнер Андресен: поэтика «изумления»// Вестник Воронежского государственного университета. Серия: Лингвистика и межкультурная коммуникация. 2021. № 2. C. 110-117. DOI: https://doi.org/10.17308/lic.2021.2/3421
12. Kant I. Nablyudeniya nad chuvstvom Prekrasnogo i Vozvyshennogo [Observations on the Feeling of the Beautiful and Sublime]. In: Kant I. Sobranie sochinenij $v 6$ tomakh [Colected edition. 6 volumes]. Ed. by V. F. Asmus, A. V. Gulyga, T. I. Ojzerman. V. 2. Moscow: Mysl', 1964. Pp. 125-185.

13. Sovremennyj tolkovyj slovar' russkogo yazyka [Modern Russian language dictionary]. Ed. by T. F. Efremova. Available at: https://dic.academic.ru/contents.nsf/efremova/

14. Entsiklopedicheskij slovar' po psikhologii i pedagogike. [Encyclopedical dictionary of psychology and pedagogy]. Available at: https://psychology_pedagogy.academic.ru/

15. Lyutikova N. G. Predislovie [Introduction]. In: Rilke R. M. Kniga Obrazov [The book of images]. SaintPetersburg: Tertsiya, Kristall, 1999. Pp. 5-8.

16. Heidegger M. Vremya i bytie [Being and time]. Ed. by V. V. Bibikhin. Moscow: Respublika, 1993. Pp. 259-273.

17. Bonafim Felizardo A. O Lugar do Ser: espaço e lirismo em Sophia de Mello Breyner Andresen: tese de doutoramento. São Paulo, 2012. 267 p.

18. Trishin V. N. Slovar' sinonimov ASIS [Dictionary of synonyms]. Available at: https://dic.academic.ru/contents. nsf/dic_synonims/

19. Lopes S. R. Escutar, Nomear, Fazer Paisagens. In: Exercícios de Aproximação. Lisboa: Vendaval, 2003. Pp. 49-74.

20. Tressider J. Slovar' simvolov [Dictionary of Symbols]. Translated by S. Pal'ko. Moscow: Grand : FAIR-Press, 1999. $443 \mathrm{p}$.

Moscow State Linguistic University

Nechaeva K. K., Candidate of Philology, Acting Head of the Portuguese Language Department

E-mail:nechaeva.ksk@mail.ru

Makhortova V. A., Post-graduate Student of the Portuguese Language Department

E-mail:varvara2504@mail.ru

Received: 1 February 2021

Accepted: 22 March 2021

\section{For citation:}

Nechaeva K. K., Makhortova $V$. A. Sophia de Mello Breyner Andresen: the poetry of "amazement". Proceedings of Voronezh State University. Series: Linguistics and Intercultural Communication. 2021. No. 2. Pp. 110-117. DOI: https://doi.org/10.17308/lic.2021.2/3421 